\title{
Temperature and moisture influence on the curing process of PAPR-type fertilizer products
}

\author{
Jakub Skut, Krystyna Hoffmann, Józef Hoffmann* \\ Wrocław University of Technology, Faculty of Chemistry, Institute of Inorganic Technology and Mineral Fertilizers, \\ ul. Smoluchowskiego 25, 50372 Wroctaw, Poland \\ "Corresponding author: e-mail: jozef.hoffmann@pwr.wroc.pl
}

\begin{abstract}
PAPRs (Partially Acidulated Phosphate Rocks) are the most prospective phosphate fertilizers, mainly through the use of the smaller amount of reagents and the ability to utilize low-grade phosphate rocks with a low content of $\mathrm{P}_{2} \mathrm{O}_{5}$. The aim of our studies was to investigate the temperature and moisture influence on the curing process of PAPR-type fertilizer products. Fertilizer preparations of a PAPR-type were obtained in the Atlas model-type apparatus (Syrris Ltd.). The curing temperature and the moisture content were controlled by the heating time of the reaction vessel and the degree of PAPR stoichiometric norm $\left(\eta_{\mathrm{PAPR}}\right)$. Our results indicate that increasing the curing temperature of the PAPR-type fertilizer product by $10^{\circ} \mathrm{C}$ can lead to a decrease in the moisture content of the final product by an average value of $1.5 \% \mathrm{w} / \mathrm{w}$. Additionally reducing the moisture content by $1 \% \mathrm{w} / \mathrm{w}$ may correspond to an increase in $\mathrm{P}_{2} \mathrm{O}_{5}$ content by an average value of $0.5 \% \mathrm{w} / \mathrm{w}$.
\end{abstract}

Keywords: PAPR, phosphate fertilizers, curing process, moisture content.

\section{INTRODUCTION}

In the latest report (May 3, 2011) The Department of Economic and Social Affairs United Nations predicts that in 2050 the world population will reach 9.3 billion people ${ }^{1}$. Incessant increase in agricultural productivity will therefore be essential for meeting the nutritional requirements of future inhabitants of the globe. Implementation of this objective, which was adopted as a priority in the developing countries, is currently confronted with difficulties caused by the successive reduction of available water and arable land. One of the important factors influencing the global food security is an access and efficient use of fertilizer preparations and mineral resources required for their production.

The inorganic fertilizer market is increasingly dependent on political factors. An excellent example may be industrial plants manufacturing phosphate fertilizers, whose profitability is strictly related to the current, global trends in the phosphate rock market prices. Commodities' prices for phosphate resources have been until recently continuously shaped by economic growth, agricultural production, strengthening agricultural commodities market linkages with other markets and above all, the periodic update of the world's phosphate rock reserves and resources estimates generated by the world's largest manufacturers, primarily OCP (Groupe Office Chérifien des Phosphates). The recently published report "World Phosphate Reserves and Resources" (Steven Van Kauwenbergh, IFDC, Center for Strategic \& International Studies, September 22, 2010) estimates the global phosphate rock resources at 290 billion tonnes. This indicates that the phosphate reserves are about 4 times higher (Figure 1) in relation to the commonly used as a basis the USGS data (United States Geological Survey) ${ }^{2}$.

Assuming a sustainable production, the vision of "peak phosphorus" has been dismissed for approximately 300 years ${ }^{3}$. A few months after the publication, in January 2011 USGS also introduced the updates to their widely used estimates of the world's phosphate rock reserves.

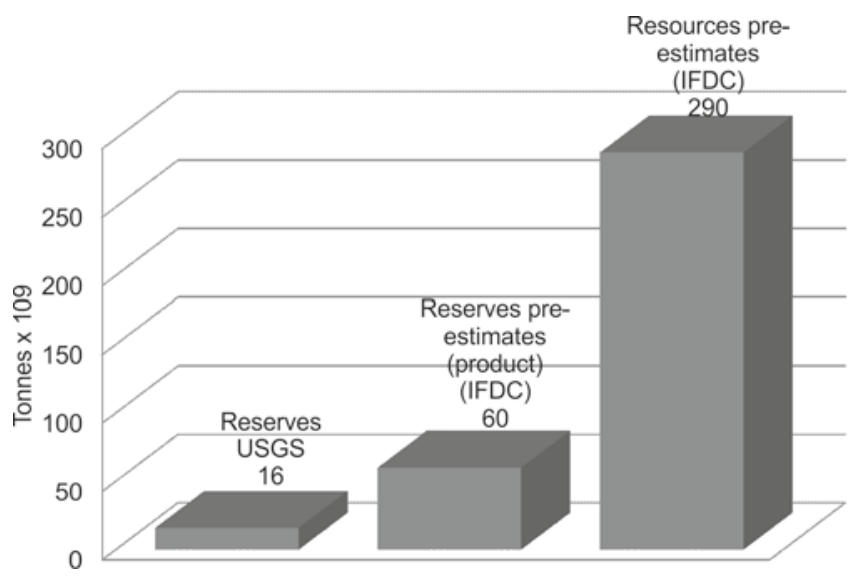

Figure 1. Summary of estimated world phosphate rock reserves and resources (comparison of estimates data contained in the IFDC report with existing USGS data $)^{3}$

The current value of 16 billion tonnes has increased to 65 billion tonnes of the world's reserves ${ }^{4}$. This result is consistent with the estimates data in IFDC report, supporting the USGS conclusions from the IFDC report ${ }^{3}$. Moreover, the IFA (International Fertilizer Industry Association) promotes the conclusion that nowadays the world does not face the challenge of achieving the peak of phosphate rocks production ${ }^{5}$. Despite this information and research on the new methods of phosphorus recovery, the commodities prices for phosphate rock (on the basis of "Morocco" phosphate rock 70\% BPL, \$ per tonne) from September 2010 are constantly rising: September 2010: 125 \$, July 2011: 197,5 \$ representing an increase equal to $58 \%{ }^{6-9}$.

The only way to minimize such a disadvantageous situation is striving to produce phosphate fertilizers at the lowest possible unit cost. Through the use of a smaller amount of reagents and the ability to utilize low-grade phosphate rocks regarding the lower content of $\mathrm{P}_{2} \mathrm{O}_{5}$, PAPR fertilizers (Partially Acidulated Phosphate Rock), seem to be the most prospective ones in this respect. According to European Regulation, PAPR fertilizers 
can be used as an inorganic straight fertilizer or as a component of compound primary nutrient fertilizers. In the case of straight, inorganic fertilizers, PAPRs are obtained by the partial acidulation of ground phosphate rock with sulphuric or phosphoric acid, containing calcium phosphate, tricalcium phosphate and calcium sulphate as the main components ${ }^{\mathbf{1 0}}$.

Chemistry of acidulation of apatite crystal structure is complicated. It is highly dependent on competing or synergistic factors specific to the type of phosphate rock mineral, such as porosity, surface area and impurities content, especially in the form of metal oxides of the general formula $\mathrm{R}_{2} \mathrm{O}_{3}$. Appropriate control of process parameters such as temperature profile of the reaction, residence time in the reactor and the moisture content allows to modify the impact of these factors, enabling a maximum efficiency of insoluble fluorapatite (solubility product of about $10^{-118}$ ) conversion into the forms available for plants i.e. soluble monocalcium phosphate $\left(\mathrm{Ca}\left(\mathrm{H}_{2} \mathrm{PO}_{4}\right)_{2}\right)$. Reactions, in a simplified manner, can be expressed using the following equations ${ }^{\mathbf{1 1 , 1 2}}$ :

$2 \mathrm{Ca}_{5}\left(\mathrm{PO}_{4}\right)_{3} \mathrm{~F}+7 \mathrm{H}_{2} \mathrm{SO}_{4}+3 \mathrm{H}_{2} \mathrm{O} \rightarrow 3 \mathrm{Ca}\left(\mathrm{H}_{2} \mathrm{PO}_{4}\right)_{2} \cdot \mathrm{H}_{2} \mathrm{O}$

$+7 \mathrm{CaSO}_{4}+2 \mathrm{HF}$

$\mathrm{Ca}_{5}\left(\mathrm{PO}_{4}\right)_{3} \mathrm{~F}+7 \mathrm{H}_{3} \mathrm{PO}_{4}+5 \mathrm{H}_{2} \mathrm{O} \rightarrow 5 \mathrm{Ca}\left(\mathrm{H}_{2} \mathrm{PO}_{4}\right)_{2} \mathrm{H}_{2} \mathrm{O}$ $+\mathrm{HF}$

The unit which defines fertilizer formulations of PAPR-type is a degree of PAPR stoichiometric norm $\left(\eta_{\text {PAPR }}\right)$ expressed as the ratio of the amount of mineral acid actually used to the stoichiometric quantity of acid required to fully acidulate a particular phosphate rock to single superphosphate (SSP):

$\eta_{P A P R}=\frac{n_{k w . \min .}^{r}}{n_{k w \text { min. }}^{s}}$

where: $\eta_{P A P R}$ is degree of PAPR stoichiometric norm, $n_{k w \text {.min. }}^{r}$ - amount of mineral acid actually used in the acidulation process, $n_{k w \text { min. }}^{s}$ - the stoichiometric quantity of acid required to fully acidulate a particular phosphate rock to SSP. Conventional SSP in this convention reaches $\eta_{P A P R}=1$. The $\eta_{P A P R}$ value determines the content of both available and insoluble phosphate forms. Insoluble forms represent mainly unacidulated parts of phosphate rock. After the application to the soil, chemical processes and microbial mineralization take place and turn them into a reserve of phosphorus compounds. Therefore, in recent years, interest in PAPR fertilizers has been constantly growing ${ }^{\mathbf{1 3 , 1 4}}$,

This paper focuses on the curing process of PAPR-type phosphate fertilizers. After initiation by mixing phosphate rock with sulphuric acid, the process of acidulation progresses the reaction of free phosphoric acid with unacidulated phosphate rock in the liquid phase. The temperature, concentration of sulphuric acid, and the $\eta_{P A P R}$ value have significant impact on this process. As a result of exothermic effect of the reactions the temperature of reacting mass fluctuates at around $100^{\circ} \mathrm{C}$. Therefore, a certain amount of water in gas phase is emitted causing water loss from the system. This phenomenon has a significant influence, particularly in the context of a PAPR fertilizers, due to the use of nonstoichiometric amounts of sulphuric acid. Limited amount of liquid phase may indeed lead to inhibition or extension of the acidulation reaction thus impairing physico-chemical properties of the final product.

\section{MATERIALS AND METHODS}

Fertilizer preparations of a PAPR-type were obtained in the model-type Atlas apparatus (Syrris Ltd.) equipped with a central unit with control panel and hot plate, a reaction vessel with the working volume $\mathrm{V}_{\mathrm{r}}=800 \mathrm{ml}$ made from Teflon in the $1 \mathrm{~cm}$ thick aluminium jacket, and stirrer head. The control panel allowed to adjust the process parameters such as temperature, reaction time and stirring intensity. The technical specification of the applied apparatus enabled to a high degree to imitate the unit processes that occur in the technological line to manufacture conventional fertilizers in the form of phosphate rock acidulation with a mineral acid in a conical mixer, and the curing process in a Moritz-Standaert den. In this paper, the variable parameters were:

1. The curing temperature controlled by the heating time of the reaction vessel, which was: $\mathrm{t}=0$ (no heating), $\mathrm{t}=10,20,30,40$ minutes respectively;

2. The degree of PAPR stoichiometric norm $\left(\eta_{\text {PAPR }}\right)$ : $\eta_{\text {PAPR }}=0.3 ; \eta_{\text {PAPR }}=0.5$ - widely used in fertilizer industry; unprocessed phosphate rock adopted as the initial state of the system, and the single superphosphate (SSP) produced with the $7 \% \mathrm{w} / \mathrm{w}$ excess of $\mathrm{H}_{2} \mathrm{SO}_{4}$ in relation to a stoichiometric norm as a product of complete dissolution of apatite structure were assumed as a reference samples.

An attempt has also been made to link the evaluation of the impact of the heating time of the reactor with the analysis of fluctuations in temperature profile of the reaction mixture as a function of time. For this purpose, the laboratory unit, provided with Voltcraft IR 650-12D infrared pyrometer measuring temperature of the reactants inside the Teflon insert, was constructed. The accuracy of localization and measurement was achieved with a dual laser pointer and an adjustable emissivity factor. The "ZIN" phosphate rock samples extracted from deposits located in the eastern desert Nagev in Israel were used for the investigations. As a commercial product it is available in the processed form as a result of hydraulic and washing beneficiation. The results of the chemical analysis of the tested phosphate rock samples are summarized in Table 1.

Table 1. Chemical composition of "ZIN" phosphate rock samples

\begin{tabular}{|l|c|}
\hline Chemical analysis & Dry matter \\
\hline $\mathrm{P}_{2} \mathrm{O}_{5}$ & $29.16 \% \mathrm{w} / \mathrm{w}$ \\
\hline $\mathrm{CaO}$ & $52 \% \mathrm{w} / \mathrm{w}$ \\
\hline $\mathrm{CO}_{2}$ & $6.2 \% \mathrm{w} / \mathrm{w}$ \\
\hline $\mathrm{SiO}_{2}$ & $1.5-2.5 \% \mathrm{w} / \mathrm{w}$ \\
\hline $\mathrm{Al}_{2} \mathrm{O}_{3}$ & $0.10 \% \mathrm{w} / \mathrm{w}$ \\
\hline $\mathrm{Fe}_{2} \mathrm{O}_{3}$ & $0.12-0.5 \% \mathrm{w} / \mathrm{w}$ \\
\hline $\mathrm{MgO}$ & $0.30-0.9 \% \mathrm{w} / \mathrm{w}$ \\
\hline $\mathrm{Moisture}$ & $2.0 \% \mathrm{w} / \mathrm{w}$ \\
\hline $\mathrm{Cd}$ & $27 \mathrm{ppm}$ \\
\hline
\end{tabular}

The results of sieve analysis performed for the "ZIN" phosphate rock samples according to PN-84 C-87012.02 and PN-71 C-04501 are shown graphically in Figure $2^{\mathbf{1 5 , 1 6}}$.

A weight sample of phosphate rock $(50 \mathrm{~g})$ were subjected to acidulation reaction with sulphuric acid $\left(\mathrm{H}_{2} \mathrm{SO}_{4}\right)$ 


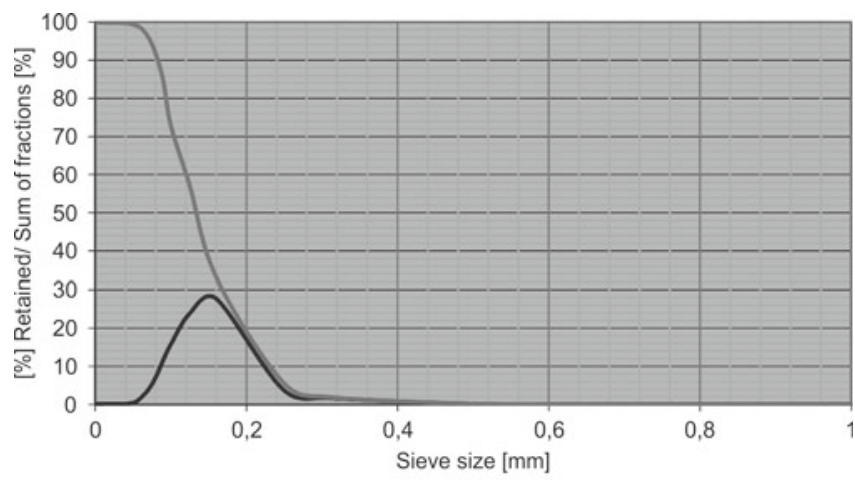

-Particle size distribution —Particle size composition

Figure 2. A graphical presentation of the results of "ZIN" phosphate rock sieve analysis

diluted to $76 \% \mathrm{w} / \mathrm{w}$. The selection of acid concentration was dictated by the initial test results, which revealed that this is the optimal value to ensure adequate diffusion of acid into the phosphate rock grains through the effective dispersion of the liquid phase in the capillaries of the whole mass of the product. Furthermore it limits the adverse effect of $\mathrm{CaSO}_{4}$ crystallization in the form of an impermeable coating around the grains ${ }^{13}$. In addition, industrial plants manufacturing phosphate fertilizers use levels of acid concentration oscillating around this value. It is also worth noting that according to the threefold classification system of phosphate rock reactivity ( $\mathrm{P}$ soluble in $2 \% \mathrm{w} / \mathrm{v}$ citric acid $(20 \mathrm{~g} / \mathrm{l}) \mathrm{P}_{2} \mathrm{O}_{5}=11.16 \%>$ 9.4; $2 \% \mathrm{w} / \mathrm{v}$ formic acid $(20 \mathrm{~g} / \mathrm{l}) \mathrm{P}_{2} \mathrm{O}_{5}=19.98 \%>13,0$; neutral ammonium citrate $\mathrm{P}_{2} \mathrm{O}_{5}=7.22 \%>5,4$ ) proposed by Diamond in 1979 and based on IFDC's research related to the effectiveness of the extraction media, the phosphate rock derived from Israeli deposits are of high reactivity ${ }^{14}$. According to available literature resources the assumed acid concentration fits in the range suggested for the reactive phosphate rock $(75-93 \% \mathrm{w} / \mathrm{w})^{8}$. A weighed portion $(50 \mathrm{~g})$ of phosphate rock sample was introduced into the reactor after a certain heating time of the reaction vessel which was: $\mathrm{t}=0$ (no heating), $\mathrm{t}=10$, 20,30, 40 minutes respectively. At the same time the calculated amount of $\mathrm{H}_{2} \mathrm{SO}_{4}$ at the concentration of $76 \% \mathrm{w} / \mathrm{w}$, which was diluted 1 minute before the end of heating time, was poured into the reactor. This procedure allowed, depending on the $\eta_{P A P R}$ value, to obtain the acid temperature in the range of $90-96^{\circ} \mathrm{C}$. During the first minute of fluorapatite dissolution, the reaction mixture was subjected to extensive stirring at $800 \mathrm{rpm}$, then heating was switched off and the acidulation process was carried on for another 39 minutes $\left(t_{\text {tot. }}=40\right.$ minutes) in the reactor with stirring at $100 \mathrm{rpm}$. At that time, periodical temperature measurements, using an infrared pyrometer, were made by every 30 seconds. Then the batch of the fertilizer product batch was unloaded and placed on a plastic cuvette in order to collect samples for further analysis. A series of studies were performed, comprising the following determinations:

1) $\mathrm{P}$ soluble in $2 \% \mathrm{w} / \mathrm{v}$ citric acid $(20 \mathrm{~g} / \mathrm{l})$, P water-soluble - in compliance with the procedures included in Regulation (EC) No 2003/2003 of the European Parliament and of the Council of 13 October 2003 relating to fertilizers ${ }^{\mathbf{1 0}}$.

2) $\mathrm{P}$ soluble in a mixture of mineral acids $\mathrm{HNO}_{3}: \mathrm{HCl}$ $(3: 1 \mathrm{v} / \mathrm{v})$; Spectrophotometric determination of $\mathrm{P}$ con- tent based on the formation of yellow complexes of the metavanadate-molybdate with orthophosphate ion - in compliance with the procedures included in PN-88 C-87015 - Mineral Fertilizers, Methods of phosphate content determination ${ }^{18}$.

3) The content of free acids - according to the modified acetone method, which implement a mixture of organic solvents acetone and 1,4-dioxane mixed in a volume ratio of $1: 1$ as an extraction solution. The sample was filtered and washed on the filter with acetone. The filtrate was titrated with standard $0.1 \mathrm{~N} \mathrm{NaOH}$ solution. Titration was conducted in two stages, the first against methyl red, the second against phenolphthalein as the indicator ${ }^{19}$.

4) The moisture content - according to the gravimetric method using drying at $105^{\circ} \mathrm{C}$.

\section{RESULTS AND DISCUSSION}

To illustrate the effect of temperature on the properties of the curing of PAPR-type fertilizer products the results of determinations of $\mathrm{P}$ soluble in $2 \% \mathrm{w} / \mathrm{v}$ citric acid solution and in water were referred to results of the content of $\mathrm{P}$ soluble in a mixture of mineral acids $\mathrm{HNO}_{3}+\mathrm{HCl}(3: 1 \mathrm{v} / \mathrm{v})$. During the experiment SSP was used as a reference sample. Obtained data trends are shown in Figure 3-5.

Analysis of SSP reference sample produced on the basis of $\mathrm{H}_{2} \mathrm{SO}_{4}$ with excess of $7 \%$ w/w regarding stoichiometry

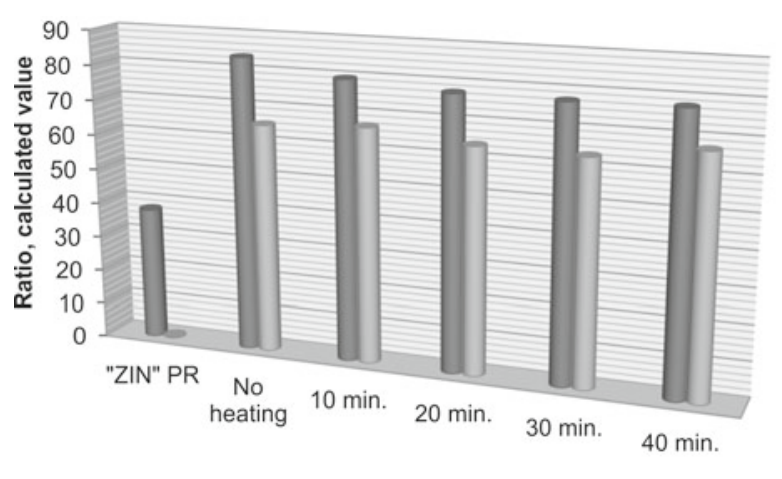

Heating time of reaction vessel

a $\mathrm{P}$ soluble i $2 \% \mathrm{w} / \mathrm{v}$ citric acid solution awater-soluble $\mathrm{P}$

Figure 3. The ratio of $\mathrm{P}$ soluble in water and $2 \% \mathrm{w} / \mathrm{v}$ citric acid solution to the content of $\mathrm{P}$ soluble in the mixture of mineral acids in reference to the heating time - SSP

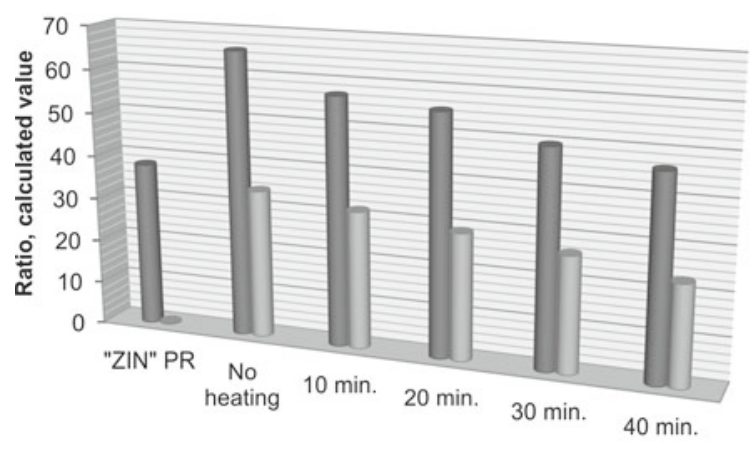

Heating time of reaction vesse

aP soluble in $2 \%$ w/v citric acid solution awater-soluble $\mathrm{P}$

Figure 4. The ratio of $\mathrm{P}$ soluble in water and $2 \% \mathrm{w} / \mathrm{v}$ citric acid solution to the content of $\mathrm{P}$ soluble in the mixture of mineral acids in reference to the heating time - PAPR $-\eta_{\text {PAPR }}=0.5$ 


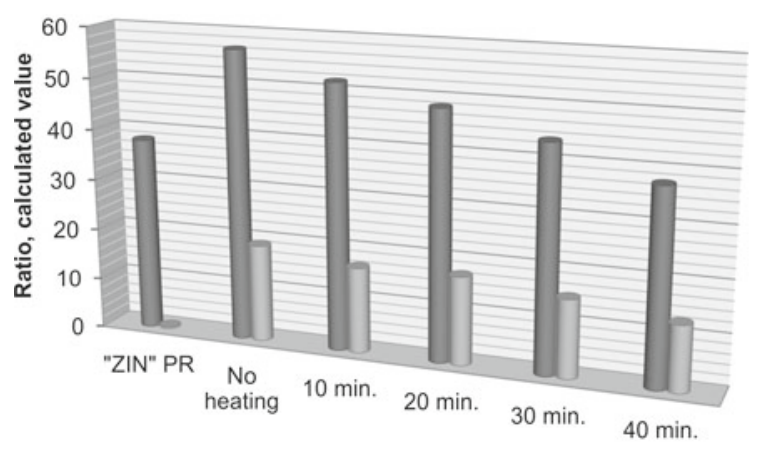

Heating time of reaction vessel

aP soluble in $2 \% \mathrm{w} / \mathrm{v}$ citric acid solution awater-soluble $\mathrm{P}$

Figure 5. The ratio of $\mathrm{P}$ soluble in water and $2 \% \mathrm{w} / \mathrm{v}$ citric acid solution to the content of $\mathrm{P}$ soluble in the mixture of mineral acids in reference to the heating time - PAPR $-\eta \mathrm{PAPR}=0.3$

of acidulation reaction showed a slight increase in the phosphorus content of the water-soluble $\mathrm{P}$ fractions during 40 minutes of product curing with reference to the rise in temperature of the process caused by prolonging the heating time of the reaction vessel. This represents an opposite trend with respect to the PAPR-type fertilizer products $\left(\eta_{\mathrm{PAPR}}=0.3 ; \eta_{\mathrm{PAPR}}=0.5\right)$, where a remarkable decrease in the content of soluble monocalcium phosphate is accompanied by a decrease of $\mathrm{P}$ soluble in $2 \% \mathrm{w} / \mathrm{v}$ citric acid solution. All fertilizer products produced under laboratory conditions were characterized by higher values of the ratio of $\mathrm{P}$ soluble in water and $2 \% \mathrm{w} / \mathrm{v}$ citric acid solution to the content of $\mathrm{P}$ soluble in the mixture of mineral acids against the heating time in comparison with the values obtained for the unprocessed "ZIN" phosphate rock samples. By correlating these results with the nature of fluctuations in moisture content in samples of PAPR and SSP fertilizers (Figure 6) indicated a significant dependence between the water loss from the system and decrease in the solubility of PAPR-type fertilizer formulations. Furthermore it was found, that the impact of this factor is lowest for the reference SSP sample, despite the most intense process of evaporation. This is due to the higher baseline level of moisture content, corresponding to the use of stoichiometric quantities of $\mathrm{H}_{2} \mathrm{SO}_{4}$, which, even under the conditions of the highest curing temperature, reaches $5.62 \mathrm{w} / \mathrm{w}$. In this case, the value of $4 \%$ $\mathrm{w} / \mathrm{w}$ was not exceeded. $4 \% \mathrm{w} / \mathrm{w}$ is regarded as the limit below which the fluorapatite dissolution reaction does not proceed due to reduction of the liquid phase. An opposite situation was noted for PAPR-type fertilizer products in which the moisture content at the heating time of the reactor $\mathrm{t}=40$ minutes, the moisture content decreases to $\eta_{\mathrm{PAPR}}=0.3: 1.46 \% \mathrm{w} / \mathrm{w} ; \eta_{\mathrm{PAPR}}=0.5: 1.87 \%$ $\mathrm{w} / \mathrm{w}$ respectively.

In order to illustrate the impact of temperature on the curing process of a PAPR-type fertilizer products in a more intelligible manner the term "acidulation ef-

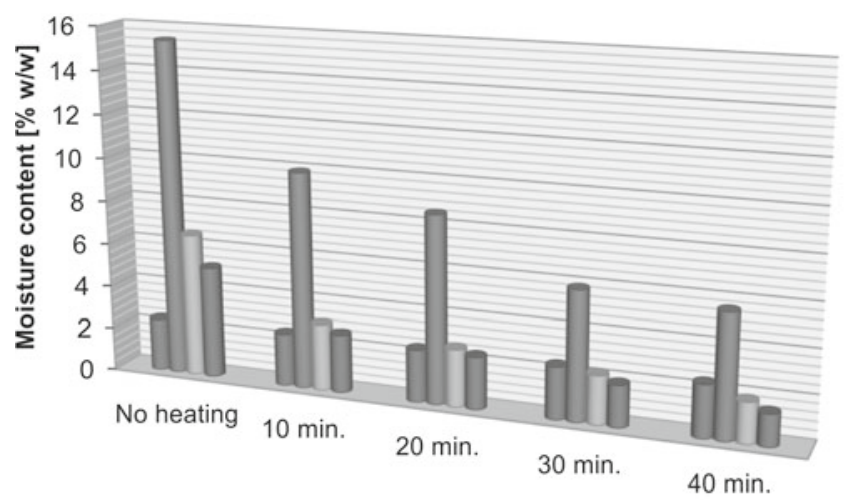

Heating time of reaction vessel

घUnprocessed "ZIN" PR घSSP anPAPR=0,5 घnPAPR=0,3

Figure 6. Summary of moisture content fluctuations in PAPRtype fertilizer products, and conventional single superphosphate (SSP) in reference to the heating time of the reactor

ficiency" was used, which describes the efficiency of the acidulation process in the conversion of insoluble forms of phosphates contained in phosphate rock to readily soluble forms. In the experiment, acidulation efficiency was assessed on the basis of water-soluble $\mathrm{P}$ (expressed as $\mathrm{P}_{2} \mathrm{O}_{5}$ ), because the calculation of the stoichiometric amount of $\mathrm{H}_{2} \mathrm{SO}_{4}$ required for a complete dissolution of phosphate rock is strictly based on the conversion of $\mathrm{P}_{2} \mathrm{O}_{5}$ contained in fluorapatite to the form of soluble monocalcium phosphate $\left(\mathrm{Ca}\left(\mathrm{H}_{2} \mathrm{PO}_{4}\right)_{2}\right)$. Calculations were made according to the following formula:

Acidulation efficiency $\left(\mathrm{P}_{2} \mathrm{O}_{\mathrm{H}_{2} \mathrm{O}}\right)=\frac{\text { water- soluble } \mathrm{P}_{2} \mathrm{O}_{5}[\% \mathrm{w} / \mathrm{w}]}{\mathrm{P}_{2} \mathrm{O}_{5} \text { soluble in } \mathrm{HNO}_{3}+\mathrm{HCl}[\% \mathrm{w} / \mathrm{w}] \times \eta_{\text {PAPR }}} \times 100$

Applying the above definition in the context of a PAPR-type fertilizer products gives closer description of the acidulation process efficiency in relation to the target $\eta_{P A P R}$ value. Table 2 depicts the results of acidulation efficiency obtained for different fertilizer products.

A distinct decrease in the phosphate rock acidulation efficiency against water-soluble $\mathrm{P}$ content could be observed during the experiments. It was a result of the increasing curing temperature level, controlled with heating time of the reaction vessel. The sample of conventional SSP presented slight increase in the same conditions, suggesting lower share of factors adversely affecting the efficiency of fluorapatite dissolution reaction with sulphuric acid. A relatively high content of liquid phase resulting from the use of $7 \% \mathrm{w} / \mathrm{w}$ excess in relation to stoichiometry allows indirectly to achieve a highly soluble fertilizer product, however, it diminishes its physical properties. The rise in the curing process temperature led to evaporation of water from the system. In consequence, the liquid phase was more concentrated with respect to free phosphoric acid, and the final product was more hygroscopic.

Fluctuations in the free acid content expressed as $\% \mathrm{H}_{3} \mathrm{PO}_{4}$ of fertilizer product dry matter (Figure 7) present a downward trend. The change in these values between the experiment carried out with (40 minutes)

Table 2. Summary results of the phosphate rock acidulation efficiency in reference to water-soluble $\mathrm{P}$ content

\begin{tabular}{|l|c|c|c|c|c|}
\hline Product type & \multicolumn{4}{|c|}{ Acidulation efficiency in reference to water-soluble P content [\%] } & \multicolumn{2}{c|}{ Change, $\Delta$} \\
\hline $\mathrm{n}_{\mathrm{PAPR}}=0.3$ & 63.6 & 55.9 & 57.5 & 50.8 & 42.8 \\
\hline $\mathrm{n}_{\mathrm{PAPR}}=0.5$ & 68.4 & 63.3 & 58.2 & 53.3 & -20.8 \\
\hline $\mathrm{SSP}$ & 65.3 & 66.8 & 64.1 & 63.5 & 46.2 \\
\hline
\end{tabular}


and without heating the reaction vessel for different fertilizer products is as follows: $\eta_{\text {PAPR }}=0.3:-0.69 ; \eta_{\text {PAPR }}=0.5$ : -1.39; SSP: -0.48 . This phenomenon is connected with the curing process of the fertilizer product. Reactions, which in the first stage consist of dissolution in the liquid phase of unacidulated fluorapatite and other compounds contained in the unprocessed phosphate rock, continue through the second stage of the precipitated phosphates separation from the liquid phase until it reaches the equilibrium level. The obtained results show that for the PAPR-type fertilizer products the content of free phosphoric acid decreases when the temperature of the curing process rises, due to extension of heating time of the reaction vessel. This phenomenon is particularly caused by the reduction of the amount of liquid phase as a result of the on-going evaporation process of unbound water from the system. It is also the result of reaction progress with unacidulated fraction of phosphate rock , when the correlation with a decrease in the content of $\mathrm{P}$ soluble in water and $2 \% \mathrm{w} / \mathrm{v}$ citric acid solution and consequently decrease in the acidulation efficiency is taken into account. In the case of SSP consistent trends were observed, whereas the levels of free phosphoric acid are significantly higher compared with the PAPR-type fertilizer products. Moreover, acidulation reaction of fluorapatite contained in phosphate rock was found to be the main factor leading to reduction of amount of free phosphoric acid in SSP product, when the increase in the content of $\mathrm{P}$ soluble in water and $2 \% \mathrm{w} / \mathrm{v}$ citric acid solution with extension of the heating time of the reactor is taken into consideration.

The results of analysis of the temperature fluctuations profile of the reaction mixture as a function of time were not enclosed in this paper due to high inertia of the model apparatus. Heat emission from the hot aluminium jacket and the interior of Teflon insert caused significant discrepancies in the results obtained for each test series.

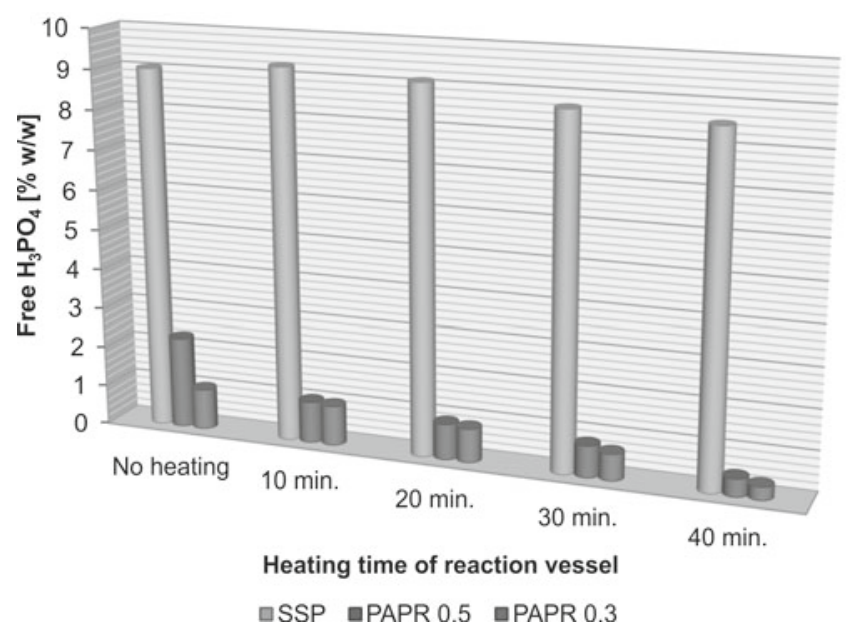

Figure 7. Summary of free phosphoric acid content fluctuations in PAPR-type fertilizer products and conventional single superphosphate (SSP) in reference to the heating time of the reactor

\section{CONCLUSIONS}

All fertilizer products produced under the laboratory conditions had higher values of the ratio of $\mathrm{P}$ soluble in water and $2 \% \mathrm{w} / \mathrm{v}$ citric acid solution with reference to the content of $\mathrm{P}$ soluble in the mixture of mineral acids as a function of heating time in comparison with the values obtained for the unprocessed "ZIN" phosphate rock samples. A distinct decrease in the phosphate rock acidulation efficiency against water-soluble $\mathrm{P}$ content, as a result of increasing curing temperature level, controlled with the heating time of the reaction vessel, was indicated in the course of performed examinations. It consistently determines the decrease of the content of $\mathrm{P}$ soluble in $2 \% \mathrm{w} / \mathrm{v}$ citric acid solution and free phosphoric acid. The reason for this phenomenon lies in the progressive water loss from the system due to the evaporation process. This reduces significantly the amount of the liquid phase required to support the first stage of fluorapatite acidulation with sulphuric acid. In consequence the obtained product has appropriate physical properties but an unfavourably high content of unacidulated phosphate rock. According to examinations performed in scope of this research, increasing the curing temperature of the PAPR-type fertilizer product by $10^{\circ} \mathrm{C}$ can lead to decrease in moisture content in the final product by an average value of $1.5 \% \mathrm{w} / \mathrm{w}$. Reducing the moisture content by $1 \% \mathrm{w} / \mathrm{w}$ may correspond to an increase in $\mathrm{P}_{2} \mathrm{O}_{5}$ content by an average value of $0.5 \% \mathrm{w} / \mathrm{w}$. Results of analyses described in this work will serve as an initial point for further investigations. Eventually we aim at determining the optimal conditions and time of curing process for PAPR-type fertilizer products. This will allow efficient implementation of the PAPR technology in existing fertilizer industrial systems for manufacturing conventional superphosphate fertilizers.

This scientific work was funded as a research project No. NN209 213138 by finance for science in the years 2010-2013.

\section{LITERATURE CITED}

1. U.N. Secretariat. Department of Economic and Social Affairs, Population Division. (2011, May 3). World Population Prospects The 2010 Revision. [Press Release]. Retrieved from http://esa.un.org/unpd/wpp/index.htm.

2. United States Geological Survey (2010). Mineral Commodity Summaries: Phosphate rock, Retrieved July 10, 2011, from http://minerals.usgs.gov/minerals/pubs/commodity/phosphate_rock/.

3. Van Kauwenbergh, S. . (2010). World Phosphate Rock Reserves and Resources. Technical Bulletin IFDC T-75. Muscle Shoals, USA, IFDC.

4. United States Geological Survey (2011). Mineral Commodity Summaries: Phosphate rock, Retrieved July 10, 2011, from http://minerals.usgs.gov/minerals/pubs/commodity/phosphate_rock/.

5. International Fertilizer Industry Association (2011). APA-style citations of electronic resources. Retrieved July 7, 2011, from http://www.fertilizer.org/ifa/HomePage/SUSTAINABILITY/Phosphorus-peak-phosphate.

6. The World Bank (2011). APA-style citations of electronic resources. World Development Indicators. Retrieved September 15, 2011, from http://data.worldbank.org/data-catalog/ commodity-price-data.

7. Grzmil, B. \& Wronkowski, J. (2004). Studies on magnesium-ammonium phosphate recovery from wastewater. Pol. J. Chem. Tech. 6(3), 13-15.

8. Hoffmann, J. \& Gluzińska, J. (2004). The feasibility of phosphorus compounds recovery and recycling. Pol. J. Chem. Tech. 6(2), 24-26. 
9. Krupa-Żuczek, K., Kowalski, Z. \& Wzorek, Z. (2008). Manufacturing of phosphoric acid from hydroxyapatite, contained in the ashes of the incinerated meat-bone wastes. Pol. J. Chem. Tech. 10(3), 13-20. DOI: 10.2478/v10026-008-0030-6.

10. Regulation (EC) No 2003/2003 of the European Parliament and of the Council of 13 October 2003 relating to fertilizers (Text with EEA relevance), Official Journal of the European Union, L 304, 122.

11. Schultz, J.J. (1986). Sulfuric acid-based partially acidulated phosphate rock: Its production, cost, and use. Tech. Bull. IFDC-T-31. Muscle Shoals, USA, IFDC.

12. Marshall, H.L. \& Hill, W.L. (1940). Composition and Properties of Superphosphate Effect of Degree of Acidulation on the Curing Processes. Ind. Eng. Chem. 32(9), 1224-1232. DOI: $10.1021 / \mathrm{ie} 50369 \mathrm{a} 036$.

13. Schroeder, J. (1955). Technology of phosphorus compounds (1st ed.) Poland: Wrocław. (in Polish).

14. Skut, J., Hoffmann, J. \& Hoffmann, K. (2010). The prospects for partial acidulation of phosphorus raw materials by PAPR method in fertilizer manufacturing plants. Przem. Chem. 89(4), 534-539. (in Polish).

15. Polish Committee for Standardization. (1984). Fertilizers - Methods used for measuring the physical properties of granular fertilizers - Sieve analysis. PN-C-87012-02-1984. Poland. (in Polish).

16. Polish Committee for Standardization. (1971). Sieve analysis - Guidelines for sieve analysis. PN-C-04501-1971. Poland. (in Polish).

17. Diamond, R.B. (1979). Views on marketing of phosphate rock for direct application. In IFDC, ed. Seminar on phosphate rock for direct application. Special Publication SP-1. Muscle Shoals, USA, IFDC.

18. Polish Committee for Standardization. (1988). Fertilizers - Methods used for measuring the phosphorus content. PNC-87015-1988. Poland. (in Polish).

19. Shuey, P. McG. (1925). Free acid in acid phosphate - its determination and value, J. Ind. Eng. Chem. 17(3), 269-270. DOI: $10.1021 / \mathrm{ie} 50183 \mathrm{a} 018$. 